\title{
Association of parental prepregnancy BMI with neonatal outcomes and birth defect in fresh embryo transfer cycles: a retrospective cohort study
}

\author{
Ruixue Chen ${ }^{1 \dagger}$, Lifen Chen ${ }^{1 \dagger}$, Yifeng Liu ${ }^{1}$, Feixia Wang ${ }^{1}$, Siwen Wang ${ }^{1}$, Yun Huang ${ }^{1}$, Kai-Lun Hu' ${ }^{1}$, Yuzhi Fan ${ }^{2}$,
} Ruoyan Liư', Runjv Zhang ${ }^{1,3}$ and Dan Zhang ${ }^{1,2,3^{*}}$

\begin{abstract}
Background: Parental body mass index (BMI) is associated with pregnancy outcomes. But the effect of parental prepregnancy BMI on offspring conceived via in vitro fertilization (IVF) or intracytoplasmic sperm injection (ICSI), especially the birth defect, remains to be determined. This study aimed to investigate the associations of parental prepregnancy BMI with neonatal outcomes and birth defect in fresh embryo transfer cycles.

Methods: We conducted a retrospective cohort study including 5741 couples in their first fresh IVF/ICSI cycles admitted to Women's Hospital, School of Medicine, Zhejiang University from January 2013 to July 2016. The primary outcome was birth defects, which was classified according to the International Classification of Diseases, 10th Revision. Secondary outcomes included preterm delivery rate, infant gender, birth weight, small-for-gestational age (SGA) and large-for-gestational age (LGA). Multilevel regression analyses were used to assess the associations of parental prepregnancy BMI with neonatal outcomes and birth defect.

Results: In singletons, couples with prepregnancy BMI $\geq 25 \mathrm{~kg} / \mathrm{m}^{2}$ had higher odds of LGA than those with BMI $<25 \mathrm{~kg} / \mathrm{m}^{2}$. The birth defect rate was significantly higher when paternal prepregnancy BMI $\geq 25 \mathrm{~kg} / \mathrm{m}^{2}$ in IVF cycles (aOR 1.82, 95\% Cl 1.06-3.10) and maternal BMI $\geq 25 \mathrm{~kg} / \mathrm{m}^{2}$ in ICSI cycles (aOR 4.89, 95\% Cl 1.45-16.53). For subcategories of birth defects, only the odds of congenital malformations of musculoskeletal system was significantly increased in IVF offspring with paternal BMI $\geq 25 \mathrm{~kg} / \mathrm{m}^{2}$ (aOR 4.55, 95\% Cl 1.32-15.71). For twins, there was no significant difference among four groups, except for the lower birth weight of IVF female infants.

Conclusions: Parental prepregnancy BMI $\geq 25 \mathrm{~kg} / \mathrm{m}^{2}$ is associated with higher incidence of LGA in IVF/ICSI singletons. Paternal prepregnancy BMI $\geq 25 \mathrm{~kg} / \mathrm{m}^{2}$ was likely to have higher risk of birth defect in IVF offspring than those with $\mathrm{BMI}<25 \mathrm{~kg} / \mathrm{m}^{2}$, particularly in the musculoskeletal system. It is essential for overweight or obesity couples to lose weight before IVF/ICSI treatments.
\end{abstract}

Keywords: Body mass index, Obesity, Assisted reproductive technology, Neonatal outcome, Birth defect

*Correspondence: zhangdan@zju.edu.cn

${ }^{\dagger}$ Ruixue Chen and Lifen Chen should be considered joint first author ${ }^{1}$ Key Laboratory of Reproductive Genetics (Ministry of Education), Department of Reproductive Endocrinology, Women's Hospital, Zhejiang University School of Medicine, Hangzhou 310006, Zhejiang, China Full list of author information is available at the end of the article

\section{Introduction}

Overweight and obesity are becoming one of the most important worldwide health issue. The prevalence of overweight and obesity has increased globally over the past decades [1]. In China, the proportion of adults with 
overweight has increased to $34.3 \%$ and the proportion of obesity has increased to $16.4 \%$.

Overweight and obesity are associated with the risk of many diseases, such as hypertension, cardiovascular diseases, diabetes and cancer [2-4]. In recent decades, more attention has been paid to the effects of overweight and obesity on the human reproductive function. Accumulating evidence suggest that overweight and obesity can contribute to the poor quality of oocyte and sperm, anovulation and impairment of endometrial receptivity [58]. Many studies have investigated the impact of maternal and paternal body mass index (BMI) on assisted reproductive technology (ART) treatment outcomes and neonatal outcomes, independently or combined. However, the results in these studies are not consistent. A retrospective cohort study of 12, 061 first fresh in vitro fertilization (IVF) or intracytoplasmic sperm injection (ICSI) cycles in China found that the singletons' birth weight increased with parental BMI [9]. Another retrospective analysis of 287, 213 pregnancies in London showed that maternal obesity increased the odds of emergency caesarian section and the large-for-gestational age (LGA) [10]. A meta-analysis found that increased paternal BMI is associated with higher risk of small-for-gestational age (SGA) and macrosomia [11]. Nevertheless, a number of studies observed that paternal BMI had no association with birth weight, LGA and SGA $[12,13]$.

In addition, birth defect is a global health problem which can result in death or disability of offspring. A lot of studies had discussed different maternal or paternal factors, like advanced age, lifestyle, obesity and chronic diseases, which would improve the birth defect rate of natural pregnancy or pregnancy that does not distinguish between natural and assisted reproduction [14-17]. Some research about the birth defect of ART offspring paid more attention on the effect of different types of ART procedures, such as sperm injection and frozen embryo transfer $[18,19]$. However, limited researches have examined the impact of parental prepregnancy BMI on birth defect of only ART offspring.

The current study aimed to estimate the effects of parental prepregnancy BMI on the neonatal outcomes and birth defect of offspring via IVF/ICSI. To the author's knowledge, this analysis is the first to investigate the association of paternal prepregnancy BMI with the birth defect risk of ART offspring. Analyses were also stratified by conventional IVF or ICSI to investigate potential ART procedures differences.

\section{Methods}

\section{Study design and participants}

This study was approved by the ethnic committee in Women's Hospital, School of Medicine, Zhejiang
University (reference: IRB-20200364-R) and all data were collected from the electronic medical record system in the department of Reproductive Medicine Center. Couples who underwent first IVF/ICSI fresh embryo transfer cycles with autologous oocytes from January 2013 to July 2016 were analyzed. The exclusion criteria were as follows:1) maternal age $>45$ years; 2 ) couples with severe complication before pregnancy, such as diabetes, hypertension, heart or liver disease; 3 ) couples with a history of smoking or drinking; 4) couples underwent preimplantation genetic testing; 5) data were incomplete or incorrect in the database. A history of smoking was defined as a patient who smoked 1 or more cigarettes per day for at least the previous six months [20]. A history of drinking was defined as 60 or more grams of pure alcohol on at least one single occasion in the past seven days [21].

\section{Parental prepregnancy BMI}

Prepregnancy weight and height of all couples were measured by a trained nurse. BMI was calculated as weight divided by squared height. All 5741 couples were divided into four groups based on the parental prepregnancy BMI according to the classification criteria of the World Health Organization: group A (both maternal and paternal $\mathrm{BMI}<25 \mathrm{~kg} / \mathrm{m}^{2}$ ); group B (maternal BMI $<25 \mathrm{~kg}$ / $\mathrm{m}^{2}$ and paternal $\mathrm{BMI} \geq 25 \mathrm{~kg} / \mathrm{m}^{2}$ ); group $\mathrm{C}$ (maternal BMI $\geq 25 \mathrm{~kg} / \mathrm{m}^{2}$ and paternal BMI $<25 \mathrm{~kg} / \mathrm{m}^{2}$ ); group D (both maternal and paternal BMI $\geq 25 \mathrm{~kg} / \mathrm{m}^{2}$ ).

\section{Outcomes}

The primary outcome was birth defect, which was determined by birth hospital or pediatric care center and was followed by a trained nurse up to the 3 years old of the child. It was classified according to the International Classification of Diseases, 10th Revision (ICD-10) into 9 subcategories. Two additional categories, 'any birth defect' and 'multiple birth defects', were used in our study. Any birth defect was defined as at least one subcategory of birth defects and multiple birth defects were defined as more than one subcategory of birth defects.

Secondary outcomes included live birth rate, delivery method, preterm delivery rate, infant gender, birth weight, low birth weight (birth weight $<2500 \mathrm{~g}$ ), macrosomia (birth weight $\geq 4000 \mathrm{~g}$ ), SGA and LGA. Live birth was defined as at least one live infant born at 28 weeks or more of gestation. Delivery methods include cesarean section and vaginal delivery. Preterm delivery was defined as a delivery occurring before 37 gestational weeks. The definition of SGA was the birth weight less than the 10th percentile for the gestational age and sex. LGA was defined as weighing greater than 90th percentile for the gestational age and sex. The 2014 reference of 
Chinese infants from 28 to 44 gestation weeks was used as the reference in this study [22].

\section{Covariates}

Covariates included: parental age (in years), reason for ART (ovulatory dysfunction, diminished ovarian reserve, endometriosis/tubal factor, uterine factor, male factor, unexplained), primary infertility or secondary infertility, duration of infertility (in years), number of oocytes retrieved, IVF or ICSI, number of two pronuclear (2PN) zygotes, number of embryos transferred.

\section{Statistical analyses}

SPSS statistics 22.0 (IBM) was used for all statistical data analyses. All continuous variables, such as parental age, $\mathrm{BMI}$ and birth weight were presented as the mean \pm SD and compared by means of analysis of variance. Categorical variables, such as live birth, LGA, SGA and birth defect, were presented as frequencies and percentages and compared by means of chi-square tests. Fisher's exact test was used if the number of cycles or participants in one or more categories was less than five.

Subgroup analyses was performed by the conventional IVF or ICSI and the singletons or twin delivery. Multilevel logistic regression was used to explore the effect of parental prepregnancy BMI on live birth, mode of delivery, infant gender, low birth weight, macrosomia, SGA, LGA and any birth defect, which were described as odds ratio (OR) with $95 \%$ confidence intervals (CIs). Multilevel linear regression analyses were used to investigate the association between parental prepregnancy BMI and birth weight, which was described as unstandardized regression coefficient (B) with 95\% CIs. All analyses were adjusted for parental age, type of infertility, duration of infertility, ovulatory dysfunction and endometriosis, which were described as adjusted odds ratio (aOR) or adjusted regression coefficient $(\mathrm{aB})$ with $95 \%$ CIs.

Additionally, all IVF cycles was stratified into two groups (paternal prepregnancy $\mathrm{BMI}<25 \mathrm{~kg} / \mathrm{m}^{2}$ and paternal prepregnancy BMI $\geq 25 \mathrm{~kg} / \mathrm{m}^{2}$ ) according to paternal prepregnancy BMI to dig deeper into the effect of paternal prepregnancy BMI on the subcategories of birth defects for singletons conceived via IVF. Logistic regression was used to analyze IVF cycles separately. Analyses were adjusted for parental age, maternal BMI, type of infertility, duration of infertility, ovulatory dysfunction and endometriosis. $P$ values $<0.05$ was considered statistically significant and all tests were 2 -tailed.

\section{Results}

\section{Characteristics of study population}

Among 5741 couples enrolled in this study, 4175 couples $(72.7 \%)$ underwent IVF treatment and 1566 couples
(27.3\%) underwent ICSI treatment. The included couples delivered 2583 neonates (1534 singletons, 1046 twins and 3 triplets). 1366 singletons and 952 twins have information about birth defect (Fig. 1).

Table 1 showed baseline characteristics of all included couples compared by parental prepregnancy BMI. The parental age and duration of infertility were significantly higher among group $\mathrm{B}, \mathrm{C}$ and $\mathrm{D}$ compared with group A (all $P<0.001$ ). There were significant differences in the proportion of primary infertility, ovulatory dysfunction, endometriosis and ART method across the parental prepregnancy BMI categories (all $P<0.05$ ). No difference appeared across the BMI categories when comparing the proportion of diminished ovarian reserve, tubal factor, uterine factor, male factor and unexplained infertility.

\section{Cycle outcomes}

The IVF/ICSI treatment outcomes are summarized in Table S1. No significant difference in the number of oocytes retrieved, $2 \mathrm{PN}$ rate, number of embryos transferred and clinical pregnancy rate were observed among four groups. Compared with group A, couples in group $\mathrm{B}, \mathrm{C}$ and $\mathrm{D}$ were more likely to have lower live birth rate ( $38.1 \%$ vs $36.4 \%$ vs $31.6 \%$ vs $31.7 \%, P=0.022$ ) when analyzing IVF cycles only. After adjustment for parental age, duration of infertility, type of infertility, women with ovulatory dysfunction and endometriosis, couples with maternal prepregnancy $\mathrm{BMI} \geq 25 \mathrm{~kg} / \mathrm{m}^{2}$ was associated with lower live birth rate compared with both parental prepregnancy BMI $<25 \mathrm{~kg} / \mathrm{m}^{2}$ (group C vs. group A: aOR $0.79,95 \%$ CI $0.63-0.99$ ).

\section{Neonatal outcomes}

We analyzed the clinical data of 1534 singletons and 1046 twins (Table 2). For singletons, the proportion of female newborns and incidence of cesarean section and fetal macrosomia varied significantly among parental prepregnancy BMI categories in IVF subgroup $(P<0.05)$. No significant difference was observed for birth weight when considering all IVF or ICSI singletons. However, the birth weight of female newborns in IVF subgroup increased significantly with higher BMI categories, ranging from $3.17 \mathrm{Kg}(\mathrm{SD} 0.42)$ in group A (both parental prepregnancy $\mathrm{BMI}<25 \mathrm{~kg} / \mathrm{m}^{2}$ ) to $3.35 \mathrm{Kg}$ (SD 0.45) in group D (both parental prepregnancy BMI $\left.\geq 25 \mathrm{~kg} / \mathrm{m}^{2}\right)$. LGA occurred more frequently in higher parental prepregnancy BMI categories, with the incidence of $16.1 \%$ in group B, $21.5 \%$ in group C and $20.0 \%$ in group D compared to $10.2 \%$ in group A for IVF subgroup and the incidence of $26.2 \%$ in group C and $31.8 \%$ in group D compared to $12.4 \%$ in group A for ICSI subgroup. No significant difference in gestational age, premature birth rate, low birth weight 
9246 first fresh autologous IVF/ICSI cycles from January 2013 to July 2016.

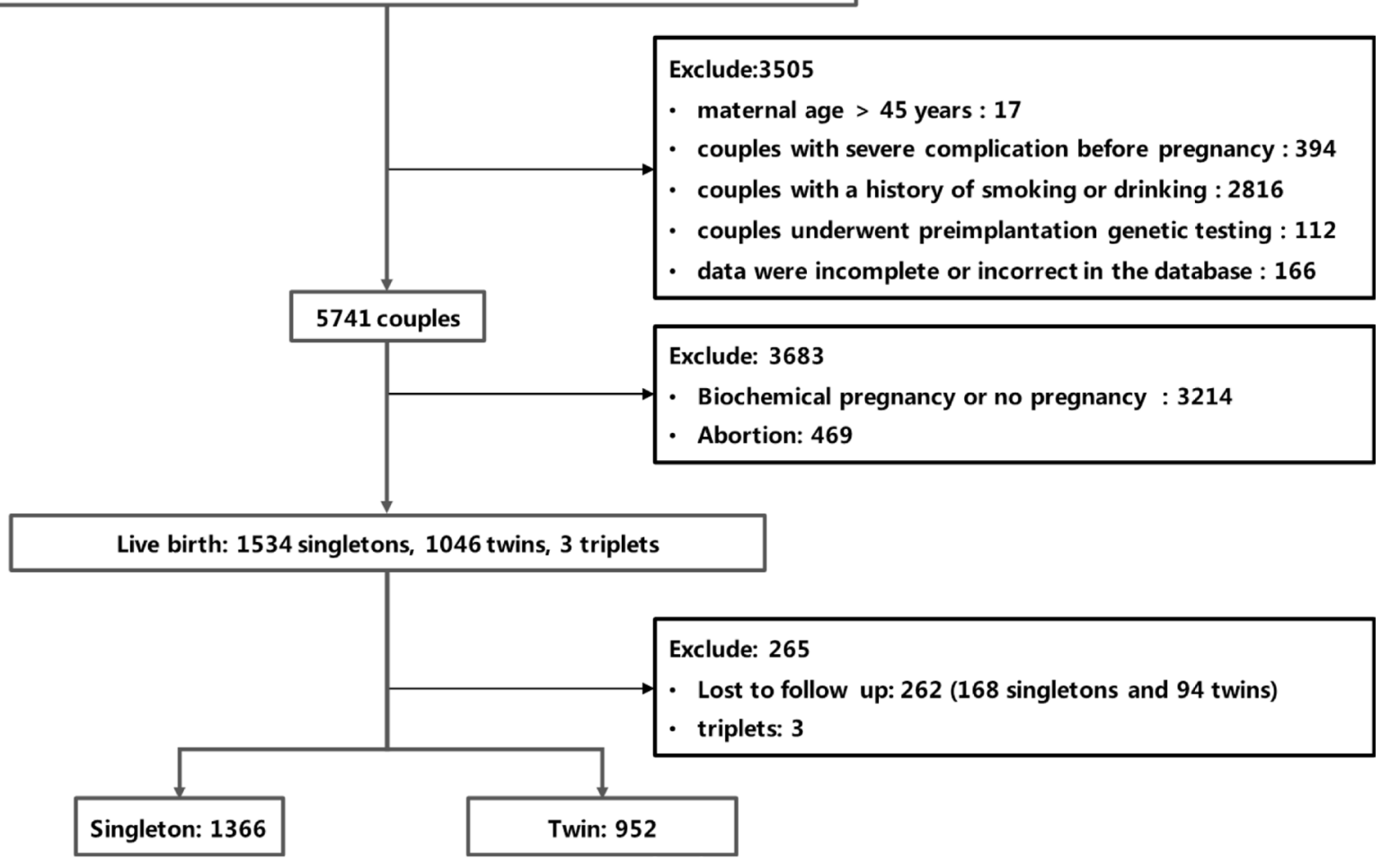

IVF, in vitro fertilization; ICSI, intracytoplasmic sperm injection.

Fig. 1 Flowchart of the study population

infant rate and SGA rate was observed among BMI categories.

For twins, except for the birth weight of female newborns and the proportion of low birth weight in IVF subgroup, there was no difference among four BMI categories.

\section{Association between parental prepregnancy BMI and neonatal outcomes}

Table 3 included details on the associations between parental prepregnancy BMI and neonatal outcomes of singletons. For IVF treatments, couples with maternal prepregnancy BMI $\geq 25 \mathrm{~kg} / \mathrm{m}^{2}$ had a trend towards an increased risk of cesarean section (aOR 1.98, 95\% CI 1.19-3.30) and a two-fold increased risk of low birth weight infant (aOR 2.42, 95\% CI 1.16-5.02) compared to couples with both parental prepregnancy BMI $<25 \mathrm{~kg} / \mathrm{m}^{2}$. Couples with both parental prepregnancy BMI $\geq 25 \mathrm{~kg} / \mathrm{m}^{2}$ had a three-fold increased risk of fetal macrosomia (aOR 3.20, 95\% CI 1.43-7.18). Higher risk of LGA was observed for couples with maternal and paternal prepregnancy $\mathrm{BMI} \geq 25 \mathrm{~kg} / \mathrm{m}^{2}$, independent or combined, than both parental BMI $<25 \mathrm{~kg} / \mathrm{m}^{2}$ (group B:
aOR 1.70, 95\% CI 1.14-2.54; group C: aOR 2.48, 95\% CI 1.41-4.36; group D: aOR 2.27, 95\% CI 1.14-4.52). Female singletons from the couples with maternal prepregnancy $\mathrm{BMI} \geq 25 \mathrm{~kg} / \mathrm{m}^{2}$ had higher birth weight ( $\mathrm{aB} 0.14$, $95 \%$ CI $0.01-0.27$ ) than both parental BMI $<25 \mathrm{~kg} / \mathrm{m}^{2}$, and similar trend was observed for couples with both parental prepregnancy $\mathrm{BMI} \geq 25 \mathrm{~kg} / \mathrm{m}^{2}$ (aB $0.20,95 \% \mathrm{CI}$ 0.03-0.36) (Table S2). For ICSI treatments, couples with maternal prepregnancy BMI $\geq 25 \mathrm{~kg} / \mathrm{m}^{2}$ had a two-fold increased risk of cesarean section (aOR 2.52, 95\% CI 1.18-5.36) and a three-fold higher risk of fetal macrosomia (aOR 3.48, 95\% CI 1.32-9.19) compared to couples with both parental prepregnancy BMI $<25 \mathrm{~kg} / \mathrm{m}^{2}$. Couples with maternal prepregnancy BMI $\geq 25 \mathrm{~kg} / \mathrm{m}^{2}$ had a nearly three-fold higher risk of LGA (aOR 2.94, 95\% CI 1.27-6.81), for couples with both parental prepregnancy $\mathrm{BMI} \geq 25 \mathrm{~kg} / \mathrm{m}^{2}$ a similar trend (aOR 3.16 , 95\% CI $1.48-$ 8.76) was observed.

For twins, the linear regression results showed IVF female newborns from the couples with maternal prepregnancy $\mathrm{BMI} \geq 25 \mathrm{~kg} / \mathrm{m}^{2}$ had lower birth weight (aB -0.21, 95\% CI -0.37-(-)0.04) than both parental BMI $<25 \mathrm{~kg} / \mathrm{m}^{2}$ (Table S2). 
Table 1 Characteristics of the included couples compared by maternal and paternal prepregnancy BMI

\begin{tabular}{|c|c|c|c|c|c|}
\hline \multirow[t]{2}{*}{ Variable } & \multicolumn{4}{|c|}{ Prepregnancy BMI category $\left(\mathrm{kg} / \mathrm{m}^{2}\right)$} & \multirow[t]{2}{*}{$P$ value ${ }^{a}$} \\
\hline & $A(M \& P<25)$ & $B(M<25 \& P \geq 25)$ & $C(M \geq 25 \& P<25)$ & $D(M \& P \geq 25)$ & \\
\hline No. of cycles & 3276 & 1571 & 533 & 361 & \\
\hline Female age(y) & $30.89 \pm 4.50$ & $31.51 \pm 4.46$ & $31.39 \pm 4.68$ & $32.55 \pm 4.74$ & $<0.001$ \\
\hline Male age(y) & $32.83 \pm 5.32$ & $33.49 \pm 5.41$ & $33.70 \pm 5.52$ & $34.96 \pm 6.02$ & $<0.001$ \\
\hline Female $\mathrm{BMI}\left(\mathrm{kg} / \mathrm{m}^{2}\right)$ & $21.23 \pm 2.01$ & $21.44 \pm 1.99$ & $26.89 \pm 1.59$ & $26.99 \pm 1.75$ & $<0.001$ \\
\hline Male BMI $\left(\mathrm{kg} / \mathrm{m}^{2}\right)$ & $22.09 \pm 1.94$ & $27.27 \pm 1.96$ & $22.26 \pm 1.93$ & $27.42 \pm 2.08$ & $<0.001$ \\
\hline Type of infertility & & & & & 0.006 \\
\hline Primary & 1633(49.8) & $755(48.1)$ & $228(42.8)$ & 159(44.0) & \\
\hline Secondary & $1643(50.2)$ & $816(51.9)$ & $305(57.2)$ & 202(56.0) & \\
\hline Duration of infertility(y) & $3.72 \pm 2.78$ & $4.07 \pm 3.13$ & $4.27 \pm 3.11$ & $4.34 \pm 3.39$ & $<0.001$ \\
\hline \multicolumn{6}{|l|}{ Cause of infertility } \\
\hline Ovulatory dysfunction & $209(6.4)$ & 104(6.6) & $84(15.8)$ & $60(16.6)$ & $<0.001$ \\
\hline Diminished ovarian reserve & $248(7.6)$ & $122(7.8)$ & $28(5.3)$ & $27(7.5)$ & 0.258 \\
\hline Endometriosis & 453(13.8) & 186(11.8) & $44(8.3)$ & $27(7.5)$ & $<0.001$ \\
\hline Tubal factor & $2057(62.8)$ & 1015(64.6) & $360(67.5)$ & $230(63.7)$ & 0.163 \\
\hline Uterine factor & $257(7.8)$ & $113(7.2)$ & $47(8.8)$ & $38(10.5)$ & 0.164 \\
\hline Male factor & 1052(32.1) & $513(32.7)$ & 154(28.9) & $121(33.5)$ & 0.382 \\
\hline Unexplained & $230(7.0)$ & $98(6.2)$ & $26(4.9)$ & $23(6.4)$ & 0.275 \\
\hline ART method & & & & & 0.045 \\
\hline IVF & 2346(71.6) & 1152(73.3) & $412(77.3)$ & $265(73.4)$ & \\
\hline ICSI & $930(28.4)$ & $419(26.7)$ & $121(22.7)$ & $96(26.6)$ & \\
\hline
\end{tabular}

Values are presented as mean \pm SD or frequency (percentage)

a $P$ value is based on One-Way ANOVA for continuous variables and $x 2$ test for categorical variables across maternal and paternal prepregnancy BMI. Results in bold indicate statistical significance $(P<0.05)$

$B M I$ body mass index, $M$ maternal prepregnancy BMI, $P$ paternal prepregnancy BMI, y year; $A R T$ assisted reproductive technology, IVF in vitro fertilization, ICSI intracytoplasmic sperm injection

\section{Birth defect}

Among 1366 singletons and 952 twins with information about birth defect, 155(6.69\%) children were diagnosed as birth defect. Among all singletons, the prevalence of any birth defect was $6.67 \%$ for all IVF/ICSI offspring $(n=1366), 6.98 \%$ for IVF offspring $(n=988)$ and $5.82 \%$ for ICSI offspring $(n=378)$. Regarding twins, the prevalence of any birth defect was $6.72 \%$ for all IVF/ICSI offspring $(n=952), 7.01 \%$ for IVF offspring $(n=742)$ and $5.71 \%$ for ICSI offspring $(n=210)$.

\section{Association between parental prepregnancy BMI and birth defect}

Table 4 showed details on the associations between parental prepregnancy BMI and any birth defect. For IVF singletons, couples with paternal prepregnancy BMI $\geq 25 \mathrm{~kg} / \mathrm{m}^{2}$ had a trend towards an increased risk of any birth defect (aOR 1.82, 95\% CI 1.06-3.10) compared to couples with both parental prepregnancy BMI $<25 \mathrm{~kg} /$ $\mathrm{m}^{2}$. For ICSI singletons, couples with maternal prepregnancy BMI $\geq 25 \mathrm{~kg} / \mathrm{m}^{2}$ had a four-fold higher risk of any birth defect (aOR 4.89, 95\% CI 1.45-16.53) compared to couples with both parental prepregnancy BMI $<25 \mathrm{~kg} /$ $\mathrm{m}^{2}$. No association was seen between parental prepregnancy BMI and any birth defect of twins.

\section{Association between paternal prepregnancy BMI and birth defect}

All singletons conceived via IVF were further grouped based on paternal prepregnancy BMI as follows: 674(68.2\%) singletons with paternal prepregnancy BMI $<25 \mathrm{~kg} / \mathrm{m}^{2}$ and $314(31.8 \%)$ singletons with paternal prepregnancy BMI $\geq 25 \mathrm{~kg} / \mathrm{m}^{2}$. Table 5 included details on the association between paternal prepregnancy BMI and birth defect of IVF singletons. We found that couples with paternal prepregnancy BMI $\geq 25 \mathrm{~kg} / \mathrm{m}^{2}$ had a four-fold increased risk of congenital malformations of the musculoskeletal system (aOR 4.38, 95\% CI 1.3114.65) compared to couples with paternal prepregnancy BMI $<25 \mathrm{~kg} / \mathrm{m}^{2}$. This association still remained after adjustment for confounding factors (aOR 4.55, 95\% CI 1.32-15.71). No association was seen between paternal prepregnancy BMI and risk of other subcategories of birth defects. 


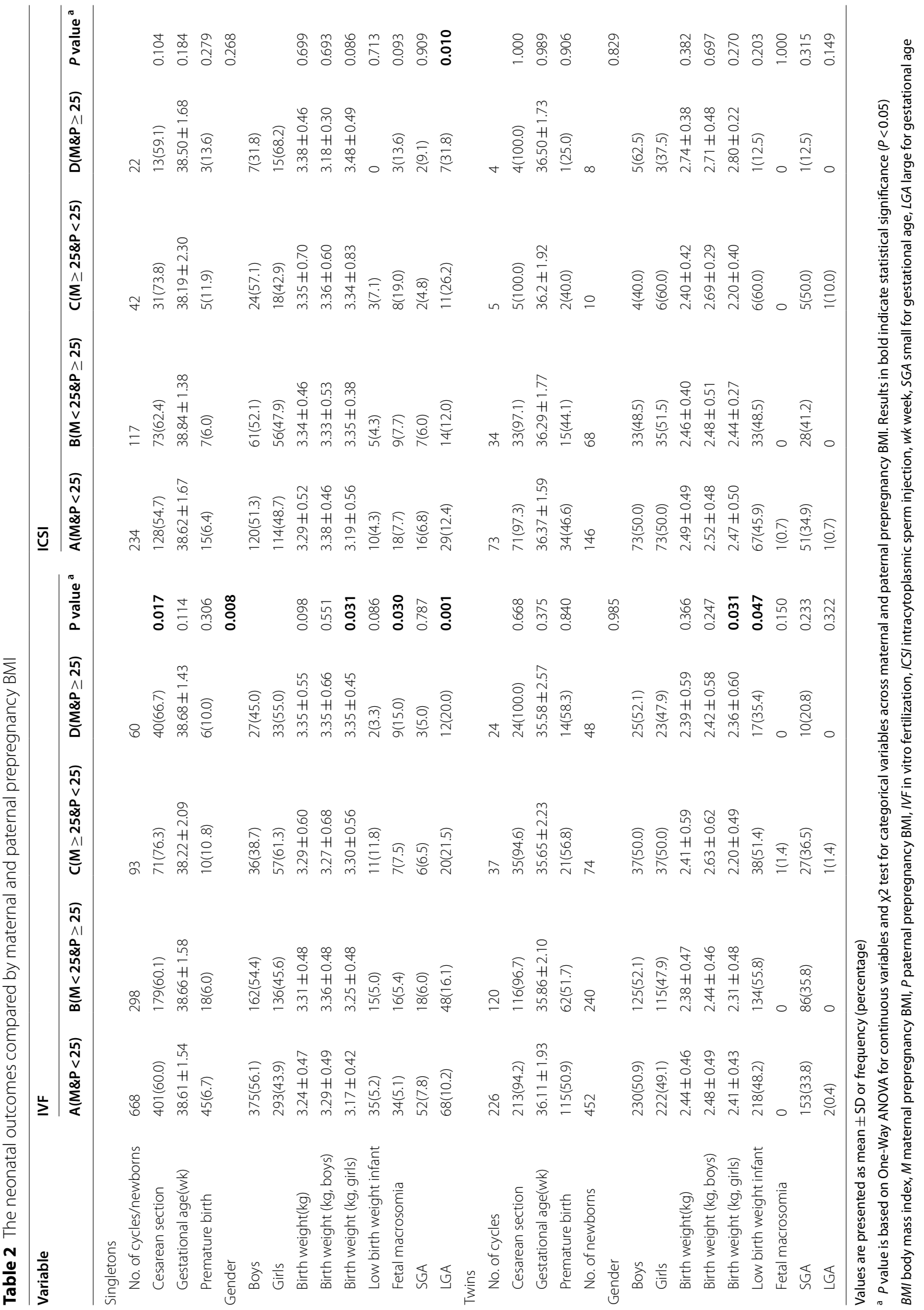


Table 3 Associations between parental prepregnancy BMI and neonatal outcomes of singletons in multilevel logistic regression analyses

\begin{tabular}{|c|c|c|c|c|c|c|c|c|}
\hline \multirow[t]{2}{*}{ Variable } & \multicolumn{4}{|l|}{ IVF } & \multicolumn{4}{|l|}{ ICSI } \\
\hline & $A(M \& P<25)$ & $\mathrm{B}(\mathrm{M}<25 \& \mathrm{P} \geq 25)$ & $C(M \geq 25 \& P<25)$ & $D(M \& P \geq 25)$ & $A(M \& P<25)$ & $\mathrm{B}(\mathrm{M}<25 \& \mathrm{P} \geq 25)$ & $C(M \geq 25 \& P<25)$ & $D(M \& P \geq 25)$ \\
\hline $\begin{array}{l}\text { Cesarean sec- } \\
\text { tion }\end{array}$ & $401(60.0)$ & $179(60.1)$ & $71(76.3)$ & $40(66.7)$ & $128(54.7)$ & $73(62.4)$ & $31(73.8)$ & $13(59.1)$ \\
\hline $\begin{array}{l}\mathrm{aOR}(95 \% \\
\mathrm{Cl})^{\mathrm{a}}\end{array}$ & REF & $0.96(0.72,1.27)$ & $1.98(1.19,3.30)$ & $1.30(0.73,2.29)$ & REF & $1.37(0.87,2.18)$ & $2.52(1.18,5.36)$ & $1.25(0.51,3.08)$ \\
\hline$P$ value ${ }^{b}$ & & 0.755 & 0.008 & 0.374 & & 0.177 & 0.017 & 0.633 \\
\hline Gender(Boys) & $375(56.1)$ & $162(54.4)$ & $36(38.7)$ & $27(45.0)$ & $120(51.3)$ & $61(52.1)$ & $24(57.1)$ & $7(31.8)$ \\
\hline $\begin{array}{l}\mathrm{aOR}(95 \% \\
\mathrm{Cl})^{\mathrm{a}}\end{array}$ & REF & $0.93(0.71,1.23)$ & $0.49(0.31,0.77)$ & $0.65(0.38,1.11)$ & REF & $1.02(0.65,1.60)$ & $1.28(0.65,2.51)$ & $0.44(0.17,1.13)$ \\
\hline Pvalue ${ }^{b}$ & & 0.617 & 0.002 & 0.113 & & 0.923 & 0.477 & 0.088 \\
\hline $\begin{array}{l}\text { Low birth } \\
\text { weight infant }\end{array}$ & $35(5.2)$ & $15(5.0)$ & $11(11.8)$ & $2(3.3)$ & $10(4.3)$ & $5(4.3)$ & $3(7.1)$ & 0 \\
\hline $\begin{array}{l}\mathrm{aOR}(95 \% \\
\mathrm{Cl})^{\mathrm{a}}\end{array}$ & REF & $0.97(0.52,1.81)$ & $2.42(1.16,5.02)$ & $0.60(0.14,2.61)$ & REF & $1.08(0.35,3.30)$ & $2.10(0.52,8.54)$ & - \\
\hline Pvalue ${ }^{b}$ & & 0.924 & 0.018 & 0.499 & & 0.897 & 0.298 & - \\
\hline $\begin{array}{l}\text { Fetal macroso- } \\
\text { mia }\end{array}$ & $34(5.1)$ & $16(5.4)$ & $7(7.5)$ & $9(15.0)$ & $18(7.7)$ & $9(7.7)$ & $8(19.0)$ & $3(13.6)$ \\
\hline $\begin{array}{l}\mathrm{aOR}(95 \% \\
\mathrm{Cl})^{\mathrm{a}}\end{array}$ & REF & $1.05(0.57,1.95)$ & $1.48(0.63,3.48)$ & $3.20(1.43,7.18)$ & REF & $1.10(0.47,2.56)$ & $3.48(1.32,9.19)$ & $1.81(0.47,6.92)$ \\
\hline$P$ value ${ }^{b}$ & & 0.866 & 0.369 & 0.005 & & 0.832 & 0.012 & 0.386 \\
\hline LGA & $68(10.2)$ & $48(16.1)$ & $20(21.5)$ & $12(20.0)$ & $29(12.4)$ & $14(12.0)$ & $11(26.2)$ & $7(31.8)$ \\
\hline $\begin{array}{l}\mathrm{aOR}(95 \% \\
\mathrm{Cl})^{\mathrm{a}}\end{array}$ & REF & $1.70(1.14,2.54)$ & $2.48(1.41,4.36)$ & $2.27(1.14,4.52)$ & REF & $1.04(0.52,2.08)$ & $2.94(1.27,6.81)$ & $3.16(1.14,8.76)$ \\
\hline$P$ value ${ }^{b}$ & & 0.009 & 0.002 & 0.020 & & 0.913 & 0.012 & 0.027 \\
\hline
\end{tabular}

Values are presented as frequency (percentage)

a aOR: Odds ratio and $95 \%$ confidence interval $(\mathrm{Cl})$ were calculated from logistic regression models to reflect the associations between parental prepregnancy BMI and neonatal outcomes of singletons. Adjusted models are controlled for parental age, type of infertility, duration of infertility, ovulatory dysfunction and endometriosis

${ }^{b} P$ value is based on multilevel logistic regression analyses. Results in bold indicate statistical significance $(P<0.05)$

$B M I$ body mass index, $M$ maternal prepregnancy BMI, $P$ paternal prepregnancy BMI, IVF in vitro fertilization, ICS/ intracytoplasmic sperm injection, $L G A$ large for gestational age, $R E F$ reference group

\section{Discussion}

As risk factors of poor reproductive condition, overweight and obesity are likely more common in infertile couples. Compared with spontaneous pregnancy, couples seeking ART treatments are more concerned about the live birth rate and the health of offspring. Our study explored the effect of parental prepregnancy BMI on the neonatal outcomes and birth defect in fresh autologous cycles, which may offer advice for improving the effectiveness of ART treatment.

Despite no significant differences in the number of oocytes retrieved, 2PN rate and clinical pregnancy rate among four groups, maternal prepregnancy BMI $\geq 25 \mathrm{~kg} /$ $\mathrm{m}^{2}$ was associated with lower live birth rate in IVF cycles. This finding is consistent with several previous published studies [23-25]. However, no significant differences were observed in the live birth rate of ICSI cycles among four groups, which is consistent with prior studies. A metaanalysis by Le et al. suggested that increased male BMI could hardly affect the live birth rate of ICSI treatment [26]. Ozgun et al. also found no significant difference in live birth rate between women with normal-weight and obesity underwent ICSI treatment [27].

After analyzing the neonatal outcomes of 1534 singletons, we observed that the proportion of LGA is significantly different across four groups in both IVF and ICSI cycles, especially the sizable increase in group $C$ and group D. It suggested that increased parental prepregnancy BMI is a risk factor of LGA. This association has been partly found in previous studies. A study by Anzola et al. concluded that the percentage of LGA was influenced by a high maternal BMI in IVF-FET cycles [28]. A retrospective analysis of 12,950 deliveries, which didn't restrict the study population to offspring conceived via $A R T$, investigated that women classified as obesity before pregnancy were at increased risk for LGA $(16.8 \%$ vs $10.5 \%$, OR $1.72,95 \%$ CI $1.57-1.97$ ) [29]. The underlying mechanism could be in part explained by insulin resistance in women with obesity which resulted in the increased nutrients supply to the fetus through the placenta [30]. The levels of tumor necrosis factor $\alpha$ (TNF- $\alpha$ ) in cord blood are higher in obese women, which is known 
Table 4 Associations between parental prepregnancy BMI and any birth defect in multilevel logistic regression analyses

\begin{tabular}{|c|c|c|c|c|c|c|c|c|}
\hline Any birth defect & Reference $\mathrm{g}$ & & & & OR $(95 \% \mathrm{Cl})^{\mathrm{a}}$ & $P_{\text {value }}{ }^{b}$ & $\operatorname{aOR}(95 \% \mathrm{CI})^{c}$ & $P$ value $^{\mathrm{b}}$ \\
\hline \multicolumn{9}{|l|}{ Singletons } \\
\hline \multirow[t]{3}{*}{ IVF } & $A(M \& P<25)$ & $35(5.8)$ & $\mathrm{B}(\mathrm{M}<25 \& P \geq 25)$ & $26(9.8)$ & $1.76(1.04,2.99)$ & 0.036 & $1.82(1.06,3.10)$ & 0.029 \\
\hline & & & $C(M \geq 25 \& P<25)$ & $5(7.1)$ & $1.25(0.47,3.30)$ & 0.652 & $1.23(0.46,3.28)$ & 0.677 \\
\hline & & & $D(M \& P \geq 25)$ & $3(6.3)$ & $1.08(0.32,3.66)$ & 0.897 & $1.18(0.34,4.04)$ & 0.797 \\
\hline \multirow[t]{3}{*}{ ICSI } & $A(M \& P<25)$ & $8(3.7)$ & $B(M<25 \& P \geq 25)$ & $8(7.2)$ & $2.02(0.74,5.53)$ & 0.172 & $2.10(0.76,5.84)$ & 0.155 \\
\hline & & & $C(M \geq 25 \& P<25)$ & $5(14.7)$ & $4.48(1.37,14.63)$ & 0.013 & $4.89(1.45,16.53)$ & 0.011 \\
\hline & & & $D(M \& P \geq 25)$ & $1(5.9)$ & $1.63(0.19,13.81)$ & 0.657 & $1.57(0.18,13.60)$ & 0.685 \\
\hline \multicolumn{9}{|l|}{ Twins } \\
\hline \multirow[t]{3}{*}{ IVF } & $A(M \& P<25)$ & $25(5.9)$ & $B(M<25 \& P \geq 25)$ & 22(9.6) & $1.69(0.93,3.07)$ & 0.086 & $1.69(0.92,3.09)$ & 0.089 \\
\hline & & & $C(M \geq 25 \& P<25)$ & $5(8.3)$ & $1.45(0.53,3.95)$ & 0.466 & $1.73(0.62,4.81)$ & 0.293 \\
\hline & & & $D(M \& P \geq 25)$ & 0 & - & - & - & - \\
\hline \multirow[t]{3}{*}{ ICSI } & $A(M \& P<25)$ & $9(7.1)$ & $B(M<25 \& P \geq 25)$ & $1(1.5)$ & $0.20(0.03,1.61)$ & 0.131 & $0.21(0.03,1.73)$ & 0.146 \\
\hline & & & $C(M \geq 25 \& P<25)$ & $1(10.0)$ & $1.44(0.16,12.71)$ & 0.740 & $2.06(0.21,20.51)$ & 0.539 \\
\hline & & & $D(M \& P \geq 25)$ & $1(12.5)$ & $1.86(0.21,16.80)$ & 0.582 & $0.89(0.09,9.20)$ & 0.925 \\
\hline
\end{tabular}

Values are presented as frequency (percentage)

a Odds ratio (OR) and 95\% confidence interval $(\mathrm{Cl})$ were calculated from logistic regression models to reflect the association between parental prepregnancy BMI and any birth defect

b $P$ value is based on logistic regression analyses. Results in bold indicate statistical significance $(P<0.05)$

c aOR: Adjusted models are controlled for parental age, type of infertility, duration of infertility, ovulatory dysfunction and endometriosis

$B M I$ body mass index, IVF in vitro fertilization, $P$ paternal prepregnancy $B M I, R E F$ reference group

Table 5 Associations between paternal prepregnancy BMI and birth defect of IVF singletons in logistic regression analyses

\begin{tabular}{|c|c|c|c|c|c|c|}
\hline \multirow[t]{2}{*}{ The subcategories of birth defect } & \multicolumn{2}{|c|}{$\operatorname{BMI}\left(\mathrm{kg} / \mathrm{m}^{2}\right)$} & \multirow[t]{2}{*}{ OR $(95 \% \mathrm{Cl})^{\mathrm{a}}$} & \multirow[t]{2}{*}{$P_{\text {value }}{ }^{b}$} & \multirow[t]{2}{*}{$\operatorname{aOR}(95 \% \mathrm{Cl})^{c}$} & \multirow[t]{2}{*}{$P$ value ${ }^{b}$} \\
\hline & $\begin{array}{l}\mathrm{P}<25 \\
(n=674)\end{array}$ & $\begin{array}{l}P \geq 25 \\
(n=314)\end{array}$ & & & & \\
\hline Multiple birth defects & $2(0.3)$ & $1(0.3)$ & $1.07(0.10,11.88)$ & 0.954 & $0.62(0.04,10.12)$ & 0.736 \\
\hline The nervous system & $5(0.7)$ & $3(1.0)$ & $1.29(0.31,5.44)$ & 0.728 & $1.38(0.32,5.99)$ & 0.665 \\
\hline Eye, ear, face and neck & $5(0.7)$ & $6(1.9)$ & $2.61(0.79,8.61)$ & 0.116 & $2.73(0.82,9.16)$ & 0.103 \\
\hline The circulatory system & $11(1.6)$ & $4(1.3)$ & $0.78(0.25,2.46)$ & 0.669 & $0.79(0.25,2.55)$ & 0.697 \\
\hline The digestive system & $3(0.4)$ & $1(0.3)$ & $0.72(0.07,6.90)$ & 0.771 & $0.78(0.08,7.62)$ & 0.831 \\
\hline The genital organs & $2(0.3)$ & 0 & - & - & - & - \\
\hline The urinary system & $6(0.9)$ & $1(0.3)$ & $0.36(0.04,2.97)$ & 0.340 & $0.45(0.05,3.84)$ & 0.468 \\
\hline The musculoskeletal system & $4(0.6)$ & $8(2.5)$ & $4.38(1.31,14.65)$ & 0.017 & $4.55(1.32,15.71)$ & 0.016 \\
\hline Chromosomal abnormalities & $4(0.6)$ & $2(0.6)$ & $1.07(0.20,5.89)$ & 0.935 & $1.03(0.18,5.90)$ & 0.976 \\
\hline Other congenital malformations & $3(0.4)$ & $5(1.6)$ & $3.62(0.86,15.24)$ & 0.080 & $3.07(0.71,13.23)$ & 0.132 \\
\hline
\end{tabular}

Values are presented as frequency (percentage)

a Odds ratio (OR) and 95\% confidence interval $(\mathrm{Cl})$ were calculated from logistic regression models to reflect the association between paternal prepregnancy $\mathrm{BMI}$ and the subcategories of birth defect. Couples with paternal prepregnancy $B M I<25 \mathrm{~kg} / \mathrm{m}^{2}$ as reference group

b $P$ value is based on logistic regression analyses. Results in bold indicate statistical significance $(P<0.05)$

c aOR: Adjusted models are controlled for parental age, maternal prepregnancy BMI, type of infertility, duration of infertility, ovulatory dysfunction and endometriosis $B M I$ body mass index, IVF in vitro fertilization, $P$ paternal prepregnancy BMI

associated with an increased risk of LGA [31]. However, there is little research on the relationship between LGA and male prepregnancy BMI in ART cycles. Although the precise mechanisms for the effect of paternal prepregnancy BMI on LGA remain unknown, it is likely that epigenetic changes such the expression of sperm
microRNAs, histone modification and DNA methylation in spermatozoa caused by paternal overweight or obesity induce the fetal overgrowth [32, 33]. Much additional research should be conducted to confirm our findings.

In this study, parental overweight or obesity was associated with the higher odds of fetal macrosomia. In the 
meanwhile, the incidence of cesarean section markedly increased with maternal prepregnancy BMI $\geq 25 \mathrm{~kg} /$ $\mathrm{m}^{2}$. Those findings are consistent with previous studies demonstrating higher incidence of fetal macrosomia and cesarean section with raised female BMI underwent IVF/ICSI treatment [10, 34-36]. Interestingly, our study showed lower proportion of male newborns with increased maternal BMI. Moreover, parental prepregnancy overweight or obesity strongly affects the birth weight of female newborns and has no significant effect on male birth weight. In previous studies, sex ratio biased towards female infants had been found in women with low prepregnancy BMI and smoking or aged parents [3739]. Women with metabolic alterations, such as diabetes, also accounted for the lower sex ratio [40]. The mechanisms of the different impact of parental overweight or obesity on male and female newborns was not clarified, which should be investigated by more researches in the future.

Regarding the neonatal outcomes of twins, only the birth weight of female infants significantly decreased for couples with maternal prepregnancy $\mathrm{BMI} \geq 25 \mathrm{~kg} /$ $\mathrm{m}^{2}$ compared with group A. Other associations between the neonatal outcomes and parental prepregnancy BMI which we found in singletons were disappeared in twins. The differences of outcomes between the singletons and twins had been discussed in several previous studies. A retrospective population-based study in Canada showed that the association of maternal obesity with adverse pregnancy outcomes in twins is weaker than that observed in singletons [41]. Another research of 12,061 first fresh IVF/ICSI cycles indicated that the birth weight of singletons was significantly higher when parental BMI were greater, but no significant differences were observed in twins [9]. The insignificant effect of parental prepregnancy BMI on the neonatal outcomes in twins may be explained by the higher risk of complications in multiple pregnancy which may override the influence of parental obesity [42-44].

Birth defect is the most important outcome in our study. The prevalence of any birth defect was $6.69 \%$ for all births in our study. It was higher than the birth defects rate $(5.6 \%)$ published by National Health Commission of China in 2012. On the one hand, many factors which are common in infertile population may improve the risk of birth defects, such as advanced age, environment pollution exposure and genetic factors [14, 45, 46]. On the other hand, the procedures of ART may be associated with a higher risk of birth defects compared with spontaneous pregnancy $[47,48]$. The prevalence of any birth defect was $8.3 \%$ in assisted conception and $5.8 \%$ in spontaneous conception according to a research of 308,974 births in South Australia [48].
In our study, we observed that parental prepregnancy BMI $\geq 25 \mathrm{~kg} / \mathrm{m} 2$ was associated with a higher risk of any birth defect in IVF/ICSI offspring. Some published studies have explored the association between maternal BMI and different subcategories of birth defects. A meta-analysis of 18 studies investigated that women with obesity were more likely to an infant with neural tube defects (OR 1.87, 95\% CI 1.62-2.15), cardiovascular anomalies (OR 1.30, 95\% CI 1.12-1.51) and other structural anomalies than mothers with normal BMI [17]. Another research showed that mothers with obesity had an overall increased risk for having an infant with orofacial clefts [49]. However, there was limited evidence showing the association between the paternal prepregnancy BMI and birth defects before. A cohort study conducted by National Research Institute for Family Planning in China observed that the ORs of birth defect for men with overweight and obesity versus men with normal BMI was 1.12 (95\% CI 0.99-1.28) and 1.32 (95\%CI 1.05-1.64). They also found that couples with overweight or obesity had higher odds of adverse pregnancy outcomes than couples with normal BMI [50]. Van et al. found no significant association between increased paternal prepregnancy BMI and anorectal malformation [51]. Nevertheless, those studies did not distinguish between spontaneous pregnancy and assisted pregnancy. To our knowledge, our study provides the first measurements of the association between birth defects of offspring conceived via IVF/ICSI and increased paternal prepregnancy BMI.

On further subcategory analysis, we found that paternal overweight or obesity was associated with a higher risk of congenital malformations of musculoskeletal system. A rat model study proposed that impaired muscle growth at $8 \mathrm{wk}$. of age in offspring from obese fathers is driven by a decrease in GH secretion and IGF-I level [52]. Some studies had indicated that paternal obesity can reduce skeletal muscle insulin sensitivity $[53,54]$. No previous research had investigated the effect of paternal obesity on the fetal skeletal muscle development. Thus, additional studies are needed to determine the underlying mechanisms responsible for such an association.

There are some limitations in our study. One is that the sample size was small, especially of the subgroup of twins or ICSI. It may prevent us from accurately assessing the impact of increased parental prepregnancy BMI on neonatal outcomes and birth defects. Another limitation is that the study is retrospective cohort study. Part of the information about birth defects was collected by nurse via telephone, which may introduce recall bias. We tried to reduce risk of bias by explaining in detail the definition of birth defects and repeatedly confirming whether there is a hospital diagnosis certificate. Additionally, there is little research on the relationship between paternal 
prepregnancy BMI and birth defects of offspring after IVF/ICSI at present. More studies about this issue must be conducted in the future.

\section{Conclusion}

In summary, our study indicates that parental prepregnancy overweight or obesity has adverse effect on the neonatal outcomes and birth defect in fresh autologous cycles. Increased parental prepregnancy BMI, independently or combined, improves the odds of LGA and birth defect in singletons. For couples underwent IVF treatments, paternal prepregnancy BMI $\geq 25 \mathrm{~kg} / \mathrm{m}^{2}$ have higher risk of the incidence of congenital malformations of the musculoskeletal system. As a rare study investigating the effect of paternal prepregnancy BMI on the birth defects, our study could serve as a reference for further research. According to findings from our study and previous studies, couples planning to get pregnant should be advised to control their weight before pregnancy. Strengthening public health education about balanced diet and healthy lifestyle may contribute to the prevention of birth defect.

\section{Abbreviations}

BMI: Body mass index; IVF: In vitro fertilization; ICSI: Intracytoplasmic sperm injection; ART: Assisted reproductive technology; SGA: Small for gestational age; LGA: Large for gestational age; 2PN: Two pronuclear; SD: Standard deviation; Cls: Confidence intervals; OR: Odds ratio; aOR: Adjusted odds ratio.

\section{Supplementary Information}

The online version contains supplementary material available at https://doi. org/10.1186/s12884-021-04261-y.

Additional file 1: Table S1. The cycle outcomes compared by maternal and paternal prepregnancy BMI.

Additional file 2: Table S2. Associations between parental prepregnancy BMI and birth weight of IVF female newborns in multilevel linear regression analyses.

\section{Acknowledgements}

The authors are grateful to Dr. Yimin Zhu, Dr. Huijuan Gao, Dr. Yanjun Hu, Fang Zhang, Saijun Sun and other colleagues of the Department of Reproductive Endocrinology in Women's Hospital, School of Medicine, Zhejiang University for providing help during the data collection. Moreover, the authors thank all patients included in this study.

\section{Authors' contributions}

DZ, RXC and LFC contributed to the conception and design. RXC, LFC, YFL, FXW, SWW, YH and KLH contributed to the data collection. RXC, LFC, YZF and RYL contributed to statistical analyzing. RXC and LFC contributed to article writing. DZ, YFL, KLH and RJZ contributed to revising the article. All authors read and approved the final manuscript.

\section{Funding}

This work was supported by grants from the National Key Research and Development Program of China (No. 2018YFC1005003) and the National Natural Science Foundation of China (No. 81771535, 81901448).

\section{Availability of data and materials}

The datasets used and/or analyzed during the current study are available from the corresponding author on reasonable request.

\section{Declarations}

Ethics approval and consent to participate

This study was conducted in accordance with the Declaration of Helsinki and was approved by the Ethnic Committee of the Women's Hospital, School of Medicine, Zhejiang University (Number: IRB-20200364-R). All data were collected from the electronic medical record system in the department of Reproductive Medicine Center. Data were anonymized and de-identified before analysis. The Ethnic Committee of the Women's Hospital, School of Medicine, Zhejiang University (Number: IRB-20200364-R) provided a waiver of written informed consent for this study.

\section{Consent for publication}

Not applicable.

\section{Competing interests}

The authors declare that they have no competing interests.

\section{Author details}

${ }^{1}$ Key Laboratory of Reproductive Genetics (Ministry of Education), Department of Reproductive Endocrinology, Women's Hospital, Zhejiang University School of Medicine, Hangzhou 310006, Zhejiang, China. ${ }^{2}$ School of Medicine, Zhejiang University, Hangzhou 310058, Zhejiang, China. ${ }^{3}$ Women's Reproductive Health Research Key Laboratory of Zhejiang Province, Women's Hospital, Zhejiang University School of Medicine, Hangzhou 310006, Zhejiang, China.

Received: 28 August 2021 Accepted: 9 November 2021

Published online: 27 November 2021

References

1. Bentham J, Di Cesare M, Bilano V, Bixby H, Zhou B, Stevens GA, et al. Worldwide trends in body-mass index, underweight, overweight, and obesity from 1975 to 2016: a pooled analysis of 2416 population-based measurement studies in 128.9 million children, adolescents, and adults. Lancet. 2017;390(10113):2627-42.

2. Hubert HB, Feinleib M, McNamara PM, Castelli WP. Obesity as an independent risk factor for cardiovascular disease: a 26-year follow-up of participants in the Framingham heart study. Circulation. 1983;67(5):968-77.

3. Calle EE, Kaaks R. Overweight, obesity and cancer: epidemiological evidence and proposed mechanisms. Nat Rev Cancer. 2004;4(8):579-91.

4. Field AE, Coakley EH, Must A, Spadano JL, Laird N, Dietz WH, et al. Impact of overweight on the risk of developing common chronic diseases during a 10-year period. Arch Intern Med. 2001;161(13):1581-6.

5. Metwally M, Li TC, Ledger WL. The impact of obesity on female reproductive function. Obes Rev. 2007;8(6):515-23.

6. Robker RL. Evidence that obesity alters the quality of oocytes and embryos. Pathophysiology. 2008;15(2):115-21.

7. Sermondade N, Faure C, Fezeu L, Shayeb AG, Bonde JP, Jensen TK, et al. BMI in relation to sperm count: an updated systematic review and collaborative meta-analysis. Hum Reprod Update. 2013;19(3):221-31.

8. Bellver J, Pellicer A, García-Velasco JA, Ballesteros A, Remohí J, Meseguer M. Obesity reduces uterine receptivity: clinical experience from 9,587 first cycles of ovum donation with normal weight donors. Fertil Steril. 2013;100(4):1050-8.

9. Wang X, Hao J, Zhang F, Li J, Kong H, Guo Y. Effects of female and male body mass indices on the treatment outcomes and neonatal birth weights associated with in vitro fertilization/intracytoplasmic sperm injection treatment in China. Fertil Steril. 2016;106(2):460-6.

10. Sebire NJ, Jolly M, Harris JP, Wadsworth J, Joffe M, Beard RW, et al. Maternal obesity and pregnancy outcome: a study of 287,213 pregnancies in London. Int J Obes. 2001;25(8):1175-82.

11. Campbell JM, McPherson NO. Influence of increased paternal BMI on pregnancy and child health outcomes independent of maternal 
effects: a systematic review and meta-analysis. Obes Res Clin Pract. 2019;13(6):511-21.

12. Magnus P, Gjessing HK, Skrondal A, Skjærven R. Paternal contribution to birth weight. J Epidemiol Community Health. 2001;55(12):873-7.

13. Takagi K, Iwama N, Metoki H, Uchikura Y, Matsubara Y, Matsubara K, et al. Paternal height has an impact on birth weight of their offspring in a Japanese population: the Japan environment and Children's study. J Dev Orig Health Dis. 2019;10(5):542-54.

14. Yang Q, Wen SW, Leader A, Chen XK, Lipson J, Walker M. Paternal age and birth defects: how strong is the association? Hum Reprod. 2007;22(3):696-701.

15. Pierik FH, Burdorf A, Deddens JA, Juttmann RE, Weber RFA. Maternal and paternal risk factors for cryptorchidism and hypospadias: a case-control study in newborn boys. Environ Health Perspect. 2004;112(15):1570-6.

16. Vereczkey A, Gerencsér B, Czeizel AE, Szabó I. Association of certain chronic maternal diseases with the risk of specific congenital heart defects: a population-based study. Eur J Obstet Gynecol Reprod Biol. 2014;182:1-6

17. Stothard KJ, Tennant PWG, Bell R, Rankin J. Maternal overweight and obesity and the risk of congenital anomalies: a systematic review and meta-analysis. JAMA. 2009;301 (6):636-50.

18. Yu HT, Yang Q, Sun XX, Chen GW, Qian NS, Cai RZ, et al. Association of birth defects with the mode of assisted reproductive technology in a Chinese data-linkage cohort. Fertil Steril. 2018;109(5):849-56.

19. Zhu J, Zhu Q, Wang Y, Wang B, Lyu Q, Kuang Y. Comparative study on risk for birth defects among infants after in vitro fertilization and intracytoplasmic sperm injection. Syst Biol Reprod Med. 2019;65(1):54-60.

20. World Health Organisation (WHO). Guidelines for controlling and monitoring the tobacco epidemic. 1997.

21. World Health Organisation (WHO). Global status report on alcohol and health. 2011.

22. Dai L, Deng C, Li Y, Zhu J, Mu Y, Deng Y, et al. Birth weight reference percentiles for Chinese. PLoS One. 2014;9(8):e104779.

23. Bellver J, Ayllón Y, Ferrando M, Melo M, Goyri E, Pellicer A, et al. Female obesity impairs in vitro fertilization outcome without affecting embryo quality. Fertil Steril. 2010;93(2):447-54.

24. Sermondade N, Huberlant S, Bourhis-Lefebvre V, Arbo E, Gallot V, Colombani $\mathrm{M}$, et al. Female obesity is negatively associated with live birth rate following IVF: a systematic review and meta-analysis. Hum Reprod Update. 2019;25(4):439-51.

25. Luke B, Brown MB, Stern JE, Missmer SA, Fujimoto VY, Leach R. Female obesity adversely affects assisted reproductive technology (ART) pregnancy and live birth rates. Hum Reprod. 2011;26(1):245-52.

26. Le W, Su SH, Shi LH, Zhang JF, Wu DL. Effect of male body mass index on clinical outcomes following assisted reproductive technology: a metaanalysis. Andrologia. 2016;48(4):406-24.

27. Ozgun MT, Uludag S, Oner G, Batukan C, Aygen EM, Sahin Y. The influence of obesity on ICSI outcomes in women with polycystic ovary syndrome. J Obstet Gynaecol. 2011;31(3):245-9.

28. Beltran Anzola A, Pauly V, Riviere O, Sambuc R, Boyer P, Vendittelli F, et al. Birthweight of IVF children is still a current issue and still related to maternal factors. Reprod BioMed Online. 2019;39(6):990-9.

29. Ehrenberg HM, Mercer BM, Catalano PM. The influence of obesity and diabetes on the prevalence of macrosomia. Am J Obstet Gynecol. 2004;191(3):964-8.

30. Zhao R, Xu L, Wu ML, Huang SH, Cao XJ. Maternal pre-pregnancy body mass index, gestational weight gain influence birth weight. Women Birth. 2018;31(1):e20-5.

31. Mestan K, Ouyang F, Matoba N, Pearson C, Ortiz K, Wang X. Maternal obesity, diabetes mellitus and cord blood biomarkers in large-for-gestational age infants. J Pediatric Biochem. 2016;01(03):217-24.

32. Zhao H, Zhao Y, Ren Y, Li M, Li T, Li R, et al. Epigenetic regulation of an adverse metabolic phenotype in polycystic ovary syndrome: the impact of the leukocyte methylation of PPARGC1A promoter. Fertil Steril. 2017;107(2):467-74

33. Li N, Shen Q, Hua J. Epigenetic Remodeling in Male Germline Development. Stem Cells Int. 2016;2016:3152173.

34. Zander-Fox DL, Henshaw R, Hamilton H, Lane M. Does obesity really matter? The impact of BMI on embryo quality and pregnancy outcomes after IVF in women aged $\leq 38$ years. Aust N Z J Obstet Gynaecol. 2012;52(3):270-6.
35. Weiss JL, Malone FD, Emig D, Ball RH, Nyberg DA, Comstock CH, et al. Obesity, obstetric complications and cesarean delivery rate - a population-based screening study. Am J Obstet Gynecol. 2004;190(4):1091-7.

36. Dokras A, Baredziak L, Blaine J, Syrop C, VanVoorhis BJ, Sparks A. Obstetric outcomes after in vitro fertilization in obese and morbidly obese women. Obstet Gynecol. 2006;108(1):61-9.

37. Fukuda M, Fukuda K, Shimizu T, Andersen CY, Byskov AG. Parental periconceptional smoking and male: female ratio of newborn infants. Lancet. 2002:359(9315):1407-8.

38. Juntunen KST, Kvist AP, Kauppila AJI. A shift from a male to a female majority in newborns with the increasing age of grand grand multiparous women. Hum Reprod. 1997;12(10):2321-3.

39. Nicolich MJ, Huebner WW, Schnatter AR. Influence of parental and biological factors on the male birth fraction in the United States: an analysis of birth certificate data from 1964 through 1988. Fertil Steril. 2000;73(3):487-92.

40. Crawford MA, Lowy C, Koukkou E, Poston L, Ghebremeskel K. Sex ratio of offspring of diabetics. Lancet. 1998:351(9114):1515-6.

41. Ram M, Berger H, Lipworth H, Geary M, McDonald SD, Murray-Davis B, et al. The relationship between maternal body mass index and pregnancy outcomes in twin compared with singleton pregnancies. Int J Obes. 2020:44(1):33-44.

42. Powers WF, Kiely JL. The risks confronting twins: a national perspective. Am J Obstet Gynecol. 1994;170(2):456-61.

43. Chauhan SP, Scardo JA, Hayes E, Abuhamad AZ, Berghella V. Twins: prevalence, problems, and preterm births. Am J Obstet Gynecol. 2010;203(4):305-15.

44. Schwartz DB, Daoud Y, Zazula P, Goyert G, Bronsteen R, Wright D, et al. Gestational diabetes mellitus: metabolic and blood glucose parameters in singleton versus twin pregnancies. Am J Obstet Gynecol. 1999;181(4):912-4.

45. Reefhuis J, Honein MA. Maternal age and non-chromosomal birth defects, Atlanta - 1968-2000: teenager or thirty-something, who is at risk? Birth Defects Res Part A Clin Mol Teratol. 2004;70(9):572-9.

46. Zhu H, Kartiko S, Finnell RH. Importance of gene - environment interactions in the etiology of selected birth defects. Clin Genet. 2009;75(5):409-23.

47. Olson CK, Keppler-Noreuil KM, Romitti PA, Budelier WT, Ryan G, Sparks $A E T$, et al. In vitro fertilization is associated with an increase in major birth defects. Fertil Steril. 2005;84(5):1308-15.

48. Davies MJ, Moore VM, Willson KJ, Van Essen P, Priest K, Scott H, et al. Reproductive technologies and the risk of birth defects. N Engl I Med. 2012;366(19):1803-13.

49. Cedergren M, Källén B. Maternal obesity and the risk for orofacial clefts in the offspring. Cleft Palate Craniofacial J. 2005;42(4):367-71.

50. He Y, Xie X, Tang W, Ma X. Maternal and paternal obesity and adverse pregnancy outcomes in China: a cohort study. Lancet. 2017;390(Suppl 4):52S.

51. Van Rooij IALM, Wijers CHW, Rieu PNMA, Hendriks HS, Brouwers MM, Knoers NV, et al. Maternal and paternal risk factors for anorectal malformations: a Dutch case-control study. Birth Defects Res Part A Clin Mol Teratol. 2010;88(3):152-8.

52. Lecomte V, Maloney CA, Wang KW, Morris MJ. Effects of paternal obesity on growth and adiposity of male rat offspring. Am J Physiol Endocrinol Metab. 2017:312(2):e117-25.

53. Falcão-Tebas F, Kuang J, Arceri C, Kerris JP, Andrikopoulos S, Marin $E C$, et al. Four weeks of exercise early in life reprograms adult skeletal muscle insulin resistance caused by a paternal high-fat diet. J Physiol. 2019:597(1):121-36.

54. Krout D, Roemmich JN, Bundy A, Garcia RA, Yan L, Claycombe-Larson KJ. Paternal exercise protects mouse offspring from high-fat-diet-induced type 2 diabetes risk by increasing skeletal muscle insulin signaling. J Nutr Biochem. 2018;57:35-44.

\section{Publisher's Note}

Springer Nature remains neutral with regard to jurisdictional claims in published maps and institutional affiliations. 